\title{
Avaliação do potencial de Glucona-Delta-Lactona (GDL) no controle de Staphylococcus aureus em leite
}

\section{Survey of Glucona-Delta-Lactona (GDL) in Staphylococcus aureus control in milk}

\author{
Valéria S. Alves, ${ }^{*}$ Paulo Soares da Costa, ${ }^{*}$ Paschoal G. Robbs, ${ }^{\star \star}$ Valdir Favarin**
}

\section{Resumo}

A composição do leite faz com que ele tenha destaque entre os alimentos mais nutritivos para o ser humano. Esta condição também o torna favorável ao desenvolvimento de várias espécies de microrganismos patogênicos, que podem contaminá-lo através das más condições de higiene durante sua obtenção e processamento. Leite e seus derivados freqüentemente estão envolvidos em toxinfecções alimentares, que variam desde pequenos distúrbios gastrointestinais, com possíveis náuseas, cefaléia e prostração, até casos de sérias infecções com morte. Quando a manipulação excessiva e descuidada predomina em conjunto com a falta de rigor higiênico-sanitário durante a elaboração, estes produtos, com muita freqüência, estão envolvidos em surtos de intoxicação alimentar provocada por Staphylococcus aureus. A inibição destes microrganismos causadores de toxinfecções alimentares pode ser feita através do controle de $\mathrm{pH}$ e acidez do produto. $\mathrm{O}$ efeito inibidor dos ácidos orgânicos sobre Staphylococcus aureus, em leite e em produtos de laticínios, tem sido demonstrado em trabalhos de pesquisa. Já foi comprovado que, com acidez entre 0,5 e 0,7\% (expressa em ácido lático), dependendo do tipo de produto, o desenvolvimento de $S$. aureus cessa e as contagens começam a reduzir. Um sal denominado Glucona-Delta-Lactona (GDL), precursor do ácido glucônico, vem sendo testado na elaboração de alguns tipos de queijos e na inibição do desenvolvimento de vários microrganismos nestes produtos. O presente trabalho objetivou verificar a possibilidade da utilização de GluconaDelta-Lactona como gerador de ácido glucônico, bem como o seu efeito inibidor sobre o $S$. aureus. Procurou-se avaliar o efeito inibidor de GDL em diversas concentrações $(0,5 \%, 1,0 \%, 1,5 \%, 2,0 \%$ e $2,5 \%)$ sobre o $S$. aureus FRI A- 100 em leite. Verificouse que $\circ$ GDL inibiu $S$. aureus em leite, efetivamente, a partir da concentração de 2,0\%, onde $\circ \mathrm{pH}$ atingiu $4,0,0$ que correspondeu à acidez de aproximadamente 1,72\% em ácido glucônico.

Palavras-chave: Staphylococcus aureus, acidez/pH, Glucona-Delta-Lactona (GDL),ácido glucônico.

\begin{abstract}
The milk composition makes it one of the most nutritious foods for the human being. Due to this condition, the growth of pathogen microorganism is favored, which can contaminate it through the bad conditions of hygiene during its acquisition and processing. Milk and its derivatives are frequently involved in alimentary intoxication, which very from a slight digestive disorder with possible headache, sickness and exhaustion to serious infections and death. When the excessive and neglected manipulation prevails, together with the absence of rigid hygienic and sanitary control during the elaboration, these products are often involved with alimentary intoxication outbreak provoked by Staphylococcus aureus. The inhibition of this microorganism can be held by controlling the product's $\mathrm{pH}$ and acidity. The inhibitor effect of organic acids on Staphylococcus aureus, in milk and dairy products, has been demonstrated in research projects. It is proved that when the acidity rate is between $0,5 \%$ and $0,7 \%$ (expressed in lactic acid), depending on the type of product, the Staphylococcus aureus development ceases, and the counting starts to reduce. A salt named Glucona-Delta-Lactona (GDL), precursor of gluconic acid, has been tasted in the elaboration of some types of cheese and in the growth inhibition of some microorganism in these products. This research was undertaken to check the possibility of utilization of GDL as a producer of gluconic acid, as well its inhibition effect to Staphylococcus aureus. The researches aimed to estimate the inhibition effect on Staphylococcus aureus FRI-A 100, provoked by different concentrations of GDL $(0,5 \% ; 1,0 \% ; 1,5 \% ; 2,0 \% ; 2,5 \%)$ in milk. It was verified that the GDL inhibited Staphylococcus aureus in milk as from the concentration rate of $2,0 \%$, where the $\mathrm{pH}$ reached 4,0 , which corresponded to an acidity of, approximately, $1,72 \%$ in gluconic acid.
\end{abstract}

Keywords: Staphylococcus aureus, acidity/pH, Glucona-Delta-Lactona (GDL), gluconic acid.

*Departamento de Tecnologia dos Alimentos, Faculdade de Veterinária, UFF, Rua Vital Brazil Filho no 64 - Niterói - RJ - CEP $24230-340$.

**Departamento de Tecnologia de Alimentos, UFRRJ, antiga Rod. RJ-SP Km 47 - Seropédica - RJ - CEP $23890-000$. 


\section{Introdução}

Pesquisadores afirmaram que o Staphylococcus aureus tem sido o patógeno mais freqüentemente isolado nas mastites bovinas em todo o mundo (Ferreiro,1980; Araújo, 1984; Froeder et al., 1985), verificando, inclusive, que mais de $30 \%$ dos casos desta patologia em vacas que produzem leite destinado às indústrias de queijos ocorre por ação do citado microrganismo (Abbar et al., 1986).

As intoxicações estafilocócicas envolvendo produtos lácteos constituem um sério problema para a Saúde Pública a nível mundial, havendo um grande número de surtos relatados em vários países (Bryan, 1983). No Brasil, as autoridades de Saúde Pública vêm dedicando mais atenção a este tipo de envenenamento alimentar, e vários surtos têm sido investigados (Carmo e Bergdoll,1990).

Já foi comprovado que é necessária uma contagem de, no mínimo, $10^{6}$ UFC de $S$.aureus por grama de produto, para que haja produção de toxina suficiente para causar doença (Jonhson et al., 1990). Por serem termoestáveis, um leite pasteurizado adequadamente pode conter enterotoxina estafilocócica, desde que tenham sido sintetizadas pelo agente antes do tratamento térmico (Bryan, 1983).

O efeito de seis ácidos orgânicos sobre o crescimento e a produção de enterotoxinas por cepas de $S$. aureus FRI-100, FRI-472, FRI-137 e S6. Observaram que dentre os ácidos lático, cítrico, ascórbico, acético, propiônico e pirúvico, o último foi o mais eficiente no controle do desenvolvimento da cêpa FRI-100. O ácido lático foi o mais eficiente na inibição da síntese de enterotoxinas, enquanto os ácidos acético e cítrico tiveram quase nenhum efeito sobre este aspecto (Domenech et al., 1992). Foram realizadas pesquisas sobre a concentração mínima de vários ácidos orgânicos capaz de inibir o crescimento de diversos microrganismos, entre eles $0 \mathrm{~S}$. aureus, em meio com pH entre 4 e 7, concluindo-se que os ácidos málico, tartárico, glucônico e cítrico possuem fraca atividade inibitória sobre todos os microrganismos avaliados, porém os resultados desta pesquisa sugeriram que todos os ácidos orgânicos estudados possuem alguma atividade antimicrobiana (Matsuda et al., 1995).

Já que Glucona-Delta-Lactona é rapidamente hidrolizada em ácido glucônico quando em presença de água, conforme foi observado por Stecher (1968), a presente pesquisa visou possibilitar o uso desta substância no controle de $S$. aureus em leite, oferecendo, assim, mais uma opção tecnológica na prevenção de toxinfecções alimentares de origem estafilocócica em laticínios.

\section{Material e métodos}

O experimento foi realizado no Laboratório do Ministério da Agricultura e Reforma Agrária - MARA, situado na Rua Mata Machado, n²50, Maracanã - Rio de Janeiro. Empregou-se a cepa de Staphylococcus aureus FRI-A-100 (Food Research Institute A-100, produtor de enteroxina estafilocócica tipo AEEA).
Em condições assépticas, foi inoculada em cada um dos seis erlenmeyers, contendo $300 \mathrm{~mL}$ de leite esterilizado cada um, uma alíquota predeterminada da suspensão de $S$. aureus crescida em caldo nutritivo, de forma a obter-se concentração em torno de $10^{6}$ células viáveis $/ \mathrm{mL}$ de leite.

Em cada erlenmeyer utilizou-se uma concentração diferente de GDL, a saber: 0,0 (branco) e 0,$5 ; 1,0 ; 1,5 ; 2,0$ e $2,5 \%$. Os frascos foram mantidos, após homogeneização, a $25^{\circ} \mathrm{C} \pm \pm$ $3^{\circ} \mathrm{C}$.

Procedeu-se à leitura direta para avaliação de $\mathrm{pH}$ das amostras líquidas de cada um dos seis recipientes, desde imediatamente após a adição de GDL até a sexta hora, de 30 em 30 minutos, e depois disto, de seis em seis horas, até a $24 \%$ hora, e também na $48^{\mathrm{a}}$ hora.

A acidez foi avaliada em $10 \mathrm{~mL}$ do conteúdo de cada um dos seis erlenmeyers, por titulação com $\mathrm{NaOH} \mathrm{O}, 1 \mathrm{~N}$, tendo fenolftaleína $1 \%$ como indicador. Os resultados foram expressos em porcentagem de ácido lático e glucônico.

Tanto a determinação do $\mathrm{pH}$ quanto da acidez seguiram as técnicas recomendadas pelo Laboratório Nacional de Referência Animal - LANARA (Brasil, 1981).

As análises bacteriológicas seguiram as técnicas recomendadas pelo Laboratório Nacional de Referência Animal LANARA (Brasil, 1981), sendo direcionadas à contagem de $S$. aureus. Para isto foram realizadas diversas diluições decimais em solução salina peptonada $1 \%$ esterilizada, a partir do conteúdo líquido de cada um dos seis erlenmeyrs utilizados. Foram, então, inoculados $0,1 \mathrm{~mL}$ de cada uma das diluições em placas de Petri contendo o meio Agar para Contagem Padrão (APC). O plaqueamento foi feito em duplicata, seguindo a técnica do espalhamento em superfície, desde imediatamente após a adição de GDL até a 24ª hora, de seis em seis horas. A incubação foi realizada em estufa incubadora a $37^{\circ} \mathrm{C} \# 1^{\circ} \mathrm{C}$ por 24 horas, após o que foram realizadas contagens das Unidades Formadoras de Colônias (UFC) amarelas lustrosas, convexas, com diâmetro entre 1 e $5 \mathrm{~mm}$, características da cepa empregada.

\section{Resultados e discussão}

Os valores resultantes deste experimento induzem a concluir que o desenvolvimento do $S$. aureus $\mathrm{FRI}-\mathrm{A}-100$ pode ser restringido quando a acidez atinge um nível médio de 0,70-0,85\% em ácido lático, correspondendo a 1,44-1,72\% em ácido glucônico, atingindo um pH em torno de 4,0 nestes casos, o que corresponde à concentração de $1,5-2,0 \%$ de GDL no leite.

O resultado da análise estatística mostrou haver significância ( $p<0,01$ ) para as concentrações de GDL, para o tempo decorrido após a adição de GDL e para a interação tempo vs concentração de GDL.

Para todos os tempos a regressão linear mostrou-se altamente significativa $(p<0,01)$, indicando diminuição da contagem bacteriana em função do aumento da concentração de GDL, o que é possível observar no Gráfico 1. 


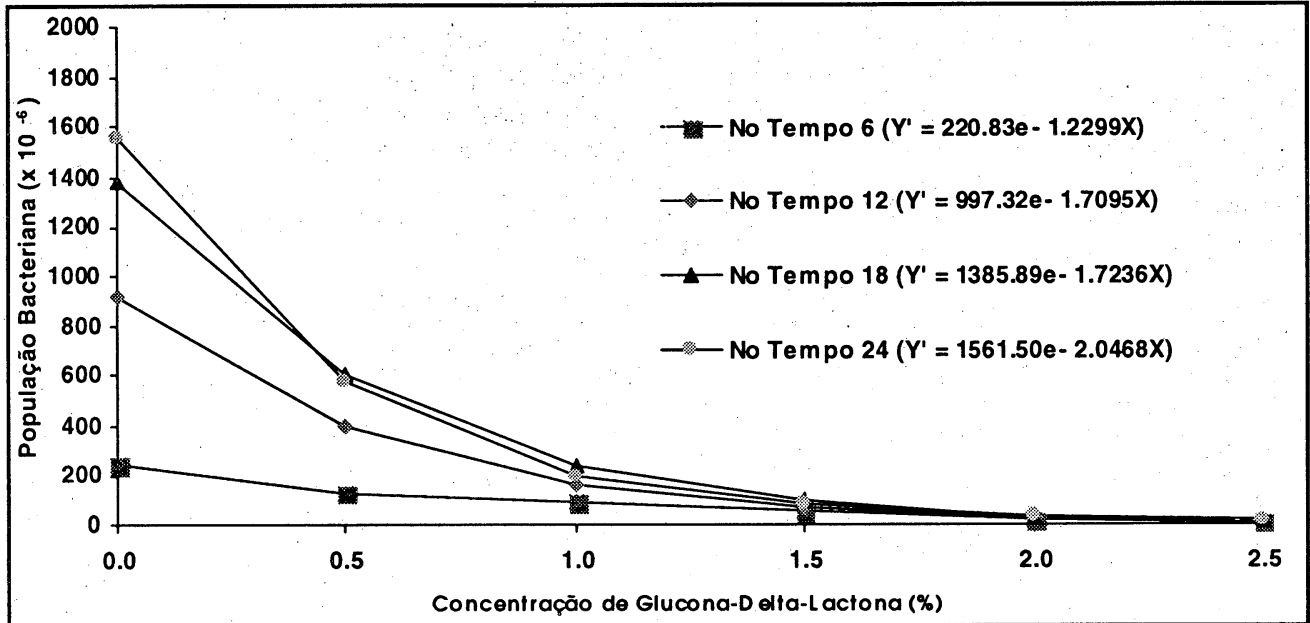

Gráfico 1 - Desenvolvimento de $S$. aureus em função da concentração de GDL, em diferentes tempos, com dados multiplicados por $10^{-6}$.
O decréscimo nas contagens de $S$. aureus de acordo com a elevação da acidez e queda de $\mathrm{pH}$ que pôde ser observado nesta pesquisa também foi constatado por Barbosa (1990). Neste, a queda nas contagens começou a ser efetiva quando a acidez atingiu $0,68 \%$ em ácido lático, só que neste caso 0 $\mathrm{pH}$ foi de 6,1 , pois estavam trabalhando com queijo parmesão. Porém, nesta pesquisà, este grau de acidez foi atingido em torno do $46^{\circ}$ dia de maturação daquele queijo, enquanto no presente trabalho este valor pôde ser observado em horas de experimento com leite.

Os resultados observados neste experimento são semelhentes aos encontrados por Gomez-Lucia et al. (1992) que, em pesquisa com o queijo Manchego, verificaram, em gráfico, que as curvas dos parâmetros de contagem de $S$. aureus vs $\mathrm{pH}$ do produto eram paralelas, ou seja, diminuindo-se o $\mathrm{pH}$, ocorria

\section{Referências}

ABBAR, F. M.; MOHAMMED, M. T. e ARSLAIN, S. H. Selected biological properties of enterotoxigenic Staphylococci isolated from milk. J. Food Prot. Ames, v. 49, n. 11, p. 871-873, nov. 1986.

ARAÚJO, W. P. Staphylococcus aureus em leite cru. Produção de exterotoxina e caracterização da origem provável, humana ou bovina, a partir das cepas isoladas. 1984. 119 p. Tese (Doutorado) São Paulo, Fac. Saúde Pública da USP.

BARBOSA, C. G. Comportamento de Staphylococcus aureus e de Escherichia coli e formação de injúria durante o período de produção dos queijos parmesão e prato. 1990.89 p. Tese (Mestrado) Rio de Janeiro, UFRRJ, Instituto de Tecnologia, Departamento de Tecnologia de Alimentos, Universidade Federal Rural do Rio de Janeiro.

BRASIL. Ministério da Agricultura. Secretaria Nacional de Defesa Agropecuária. Laboratório Nacional de Referência Animal - LANARA. Métodos analíticos oficiais para controle de produtos de origem animal e seu ingredientes. II-Métodos físicos e químicos. Brasília, DF, 1981.

. Métodos analíticos oficiais para controle de produtos de origem animal e seu ingredientes. I - Métodos microbiológicos. Brasília, DF, 1981.

BRYAN, F. L. Epidemiology of milk-borne diseases. J. Food Prot. Ames, v. 46, n. 7, p. 637-649, July, 1983.

CARMO, L. S. do e BERGDOU, M. S. Staphylococcal food poisoning in Belo Horizonte (Brazil). Rev. Microbiol. São Paulo, v. 21, p. 320-323, 1990. queda na contagem do referido microrganismo.

O efeito inibidor do ácido glucônico sobre o $S$. aureus que foi observado neste trabalho também o foi por Matsuda et al. (1995) que, inclusive, constataram a ação antimicrobiana de diversos ácidos orgânicos sobre vários microrganismos.

\section{Conclusões}

A acidez capaz de exercer o controle sobre o desenvolvimento de Staphylococcus aureus no leite, expressa em ácido glutâmico, foi entre $1,04 \%$ e $1,86 \%$, sendo mais efetiva ao nível de $1,66 \%$, o que corresponde, em ácido lático, à faixa entre $0,50 \%$ e $0,90 \%$, sendo considerado ótimo a $0,80 \%$. 0 $\mathrm{pH}$ correspondente a esta acidez encontrou-se entre 5,3 e 3,9 , sendo ótimo a 4,1 .

DOMENECH, A.; HERNANDEZ, F.J.; ORDEN, J. A.; GOYACHE, J.;LOPEZ, B.; SUÁREZ, G. e GÓMEZ-LUCÍA, E. Effect of six organic acids on staphylococcal growth and enterotoxin production. Zeitschrift für Lebensmittel, v. 194, n. 2, p. 124-128, 1992.

FERREIRO, L. Agentes etiológicos e terapêutica da mastite bovina no Brasil. Rev. Inst. Lat. Cândido Tostes. Juiz de Fora, v. 35, n. 211, p. 3741, set./out. 1980.

FROEDER, E.;PINHEIRO, A. J.R.;BRANDÃO, S. C. C. Variação da qualidade microbiológica do leite cru tipo "C" da região de Viçosa. Rev. Inst. Lat. Cândido Tostes. Juiz de Fora, v. 40, n. 241, p. 55-58, set./out. 1985.

GÓMEZ-LUCÍA, E.; GOYACHE, J.; ORDEN, J. A.; DOMENECH, A.; HERNANDEZ, F. J.; STA. QUITÉRIA, J. A. R.; LOPEZ, B.; BLANCO, J. L. e SUÁREZ, G. Growth of Staphylococcus aureus and synthesis of enterotoxin during ripening of experimental Manchego - type cheese. J. Dairy Sci. v. 75, p. 19-26, 1992.

JOHNSON, E. A.; NELSON, J. H. e JOHNSON, M. Microbiological safety of cheese made from heat-treated milk, Part. III. Technology, discussion, recommendations, bibliography. J. Food Prot. Ames, v. 53, n. 7, p. 610613, jul. 1990.

MATSUDA,T.; YANO,T;; MARUYAMA,A. \& KUMAGAI,H.. Antimicrobial activities of organic acids determined by minimum inhibitory concentrations at diferent $\mathrm{pH}$ ranged from 4.0 to 7.0. Journal of Japanese Society of Food Science and Technology. Nippon Shokuhin Kogyo Gakkaishi, v. 41, n. 10, p. 687-701, 1995.

STECHER, P. G. (Ed.). The Merck Index. $8^{\text {th }}$ ed. Rahway, N. J.: Merck and Co. Inc., 1968. 